\title{
CAPÍTULO V \\ La reinvención de saberes y los retos de la construcción de tejido social en Colombia
}

\author{
Matilde Eljach ${ }^{1}$
}

1 Doctora en Antropología, Magistra en Antropología Jurídica, Docente Investigadora de la Universidad Simón Bolívar, Grupo de Investigación Estudios Interdisciplinarios sobre el Caribe, integrante del CIISO.

matilde.eljach@unisimonbolivar.edu.co 


\title{
RESUMEN
}

La coyuntura social y política de Colombia en el contexto del proceso de paz iniciado con las FARC, plantea exigencias nuevas y complejas al ejercicio del Trabajo Social en sus estrategias de intervención social. Nuevas conceptualizaciones y apuestas metodológicas construidas en la perspectiva del enfoque decolonial, ofrecen exigencias y retos a los investigadores y gestores del trabajo con las comunidades en procura de construir y reconstruir el tejido social destruido por las múltiples formas de violencia.

Palabras clave: Intervención social, tejida social, trabajo social.

\begin{abstract}
ABSTRAC
The social and political situation in Colombia in the context of the peace process begun with the FARC, poses new and complex demands the exercise of Social Work in its social intervention strategies. New conceptualizations and built in the perspective of the decolonial approach, methodological betting offer requirements and challenges researchers and managers working with communities seeking to build and rebuild social tissue destroyed by the multiple forms of violence.
\end{abstract}

Key words: Social intervention, social tissue, social work. 


\section{Introducción}

Abordar la intervención social en el contexto del II Seminario Internacional de Trabajo Social necesariamente exige, en un primer momento, partir de una caracterización general sobre la situación de la sociedad en la que se inscribe el quehacer de las personas, organizaciones e instituciones comprometidas desde la academia y desde el agenciamiento político en la superación de condiciones críticas para el desarrollo social de un país como Colombia.

En segundo lugar, presentar fundamentaciones conceptuales que aporten elementos para avanzar con los propósitos señalados en el contexto de los objetivos del Trabajo Social con la estrategia de la intervención social, desde el modelo socio-crítico institucional, reinterpretado a la luz de las teorías críticas latinoamericanas de actualidad. En ese marco de interpretación se propone para la discusión el presente ensayo.

\section{Condiciones estructurales que generaron la violencia armada en Colombia}

Colombia ha vivido el conflicto armado más largo de la historia, marcado por la lucha agraria, la subvaloración de las necesidades sociales, la arrogancia e indiferencia de la clase política y la estrategia de acabar la guerra con más guerra, destruyendo el tejido social; históricamente ha sido un país agrario con vocación agrícola. Desde la Independencia los campesinos luchan contra la vulneración del acceso a la tierra y por la propiedad de la misma.

La lucha campesina se remonta a la historia colonial, independentista, republicana y moderna del país. Esclavizadores, hacendados, terratenientes, han explotado su trabajo como aparceros, arrendatarios, peones, jornaleros, desempleados y desplazados sin tierra (Sánchez, 2016). Como ejemplos del contexto regional, se podrían mencionar la Masacre de las Bananeras en Ciénaga Magdalena en diciembre de 1928, y las luchas lideradas por Juana Julia Guzmán en Córdoba en los inicios del siglo XX. Los campesinos colombianos desde la década de 1920, piden trabajar por derecho propio, por mejora en los salarios y condiciones de vida digna. 
En 1929 la Gran Depresión que afectó la economía del mundo, generó mayor desempleo en Colombia y caída de la producción de las haciendas cafeteras lo cual hizo florecer las luchas agrarias especialmente en Cundinamarca, Córdoba y Valle; cobra relevancia el movimiento social campesino por el derecho a la tierra, mejora en los salarios y condiciones de vida digna, así como las Reformas Agrarias propuestas para resolver la acumulación de tierra en pocas manos y la baja productividad agrícola.

Posteriormente como urgencia del Bogotazo -que derivó en violencia liberal-conservadora, en guerrillas liberales y autodefensas campesinas, y que dio origen a las FARC en 1964, según han registrado los medios de comunicación en las últimas décadas- se desarrollaron entre 1991 y 1994158 luchas agrarias, 27 paros campesinos, 82 movilizaciones campesinas, 43 tomas de instituciones estatales. Sobre los problemas agrarios, las luchas campesinas y demás expresiones del movimiento social campesino, existe una literatura profusa, sobre la cual se puede consultar a Kalmanotivtz (1978), Oquits (1978), Guzmán, Fals Borda, Umaña Luna (1977), Bagly B.M. y Botero F. (1978), entre otros.

Con la apertura neoliberal de los gobiernos Gaviria y Samper se creó la Asociación Nacional Agropecuaria, el Consejo Nacional Campesino, se promulgó el Mandato Campesino, se impulsaron movilizaciones masivas contra los efectos de los TLC y el ALCA, y por la vida digna del campesinado colombiano.

La violencia liberal-conservadora que se materializó a mediados del siglo XX asoló los campos colombianos dando surgimiento a guerrillas liberales y autodefensas campesinas; de las primeras surgieron en 1964 las FARC, las mismas con las que se ha firmado el acuerdo de paz. Las décadas siguientes no fueron ajenas a la lucha campesina; hoy se discuten las necesidades más apremiantes: realizar una verdadera reforma agraria, extinción de dominio por su uso inadecuado, fortalecimiento de las economías campesinas, reconocimiento del Estado a la dignidad de los campesinos, cese de los asesinatos, desapariciones, torturas y desplazamiento forzado, indemnización y restitución de tierras. 
Ahora bien, las condiciones más importantes que llevaron a la desmovilización de la guerrilla de las FARC y seguramente también del ELN, podrían ser: el fin de la guerra fría, el no reconocimiento de los cambios socio políticos y culturales del mundo; pérdida de respaldo financiero de países afines a su proyecto político y la toma como opción de financiarse con cultivos de uso ilícito y el narcotráfico a través de la cobra del gramaje; la corrupción de todas las esferas del Estado y de la insurgencia y contrainsurgencia; la criminalización del conflicto al enmarcarlo en secuestro-extorsión-narcotráfico, prácticas que posiblemente les reportó mucho dinero, pero les quitó legitimidad política ante la sociedad nacional e internacional, pues en Colombia la guerra se caracterizó por tener MUCHAS ARMAS pero POCA SOCIEDAD, mucha guerra y destrucción de la vida en comunidad, desplazamiento, destrozo del tejido social, cuyo ejemplo más dramático fue la masacre de Bojayá el 2 de mayo de 2002. Las FARC negocian cuando las condiciones legales, la tolerancia, la correlación de fuerzas ha cambiado (Valencia, 2016; Rivero, 2016; Parada, 2016).

Este proceso con las FARC y el ELN no es nuevo. Se han realizado en Colombia 10 procesos de paz, desde la Colonia pasando por el armisticio firmado por los cimarrones con los españoles en Cartagena comenzando el siglo XVII, la lucha de los Comuneros, las Guerras de Independencia, la violencia liberal conservadora, la guerrilla de Guadalupe Salcedo, la desmovilización del M-19 y otras organizaciones guerrilleras, hasta nuestros días.

¿Qué se acordó en este caso específico? Las FARC dejan de existir en armas, se integran al ordenamiento jurídico, no cárcel para quienes digan la verdad, amnistía a delitos conexos a la rebelión, no extradición, reparación a las víctimas y garantía de no repetición, beneficios de participación política, beneficios económicos para la reincorporación; y que el ESTADO desarrolle un amplio programa de desarrollo rural integral, así como impulsar reformas para profundizar la Democracia (Valencia 2016, Riveros 2016).

Colombia es ejemplo de la complejidad guerra-paz. La violencia se ha vivido 
como reality de televisión, nos acostumbramos a una guerra que no ha dejado atender otros problemas sociales como la inequidad, la inoperancia de la justicia, baja participación ciudadana, pobreza, corrupción, 52 años de conflicto, exclusión política y social, viejas formas de hacer política, abandono del Estado al $50 \%$ de la geografía nacional y de 15 millones de colombianos de las áreas rurales y poblaciones menores, ausencia de ciudadanía y de mercado. Poco conocimiento que tiene la guerrilla del funcionamiento del Estado y la escasa comprensión del gobierno sobre la guerrilla y su relación con la población y el territorio. Sigue primando la inmovilidad política (Parada, 2016).

En Colombia se reproduce incansablemente la paradoja de la pobreza creciente de un país con enormes recursos, con dos mares, con suficientes tierras aptas para la agricultura y enormes reservas en valles y cuencas hidrográficas, con riquezas mineras en petróleo, oro y carbón... y con todo esto, inmersos en grandes transformaciones científico-tecnológicas, se acrecienta la desigualdad y la miseria. Se atenaza más la presión de la Banca Internacional por la vía del aumento de los impuestos, se polariza con acentuado vigor el control de las minorías poderosas.

La aguda crisis socioeconómica y política que azota al país, exige rectificaciones en el terreno del manejo del problema económico y en la definición de una política transparente para el país en ese sentido, pues más que un problema económico es un problema político, y en ese marco integral se presenta el más reciente proceso de paz.

El proceso de paz no es una revolución comunista, es una ampliación de la Democracia. El acuerdo es un abrebocas para grandes transformaciones sociales, desarrollo social, inclusión, garantía de ejercicio de los derechos, reconciliación, nueva cultura política democrática.

La evolución positiva o negativa del posconflicto depende de cuánto se apropie la sociedad civil de los acuerdos y deje de ser simple espectadora de su propia historia. 
Las guerras civiles, los movimientos sociales, las olas de violencia, OBEDECEN a múltiples causas locales y regionales que confluyen a nivel nacional, en el corto, mediano y largo plazo.

La paz es la abolición del recurso de la violencia en la política en el marco constitucional, es una excelente oportunidad para construir desarrollo social, avanzar en la inclusión, construir nueva cultura política y fortalecimiento de la participación ciudadana, “... y donde las estirpes condenadas a cien años de soledad tengan por fin y para siempre una segunda oportunidad sobre la tierra..., en palabras de Gabriel García Márquez en: La soledad de América Latina, 1983.

Este es el contexto general en que urge la intervención social para la construcción y reconstrucción del tejido social que le exige a los trabajadores sociales comprensiones nuevas, conceptualizaciones y metodologías de trabajo acordes a los tiempos que caracterizan a la sociedad colombiana en su conjunto, en la construcción de un complejo proceso de paz que viabilice la superación de las diversas expresiones de violencia, en un país polarizado políticamente, con el movimiento social en reflujo, bajo la amenaza del resurgimiento de fuerzas ilegales que siguen atentando contra los gestores de paz, y enfrentando un esencialismo de buenos contra malos que no hace ningún servicio al proceso mismo.

\section{Consideraciones de orden epistemológico.}

\section{Nuevas formas de comprender la intervención social}

América fue construida conceptual, jurídica y moralmente desde los preceptos dominantes en la Conquista y en la Colonia, sin considerar los elementos existentes en las culturas indígenas y mucho menos los aportados por los africanos esclavizados provenientes de las costas occidentales y de la región subsahariana (Eljach, 2006). De allí que los marcos de interpretación conceptual y cultural sean predominantemente las aportadas por el colonizador.

Este enfoque epistemológico impuso sus cánones cognoscitivos, que respon- 
den al conocimiento "universal" construido por el pensamiento homogenizante de la época; y desde tal perspectiva, argumentaron la invalidez del conocimiento originario indoamericano y negroafricano, sus propios sentidos y construcciones. La dominación y exclusión de los otros no europeos -amerindios y africanos- es condición necesaria de la modernidad; de allí la subalternización de saberes y culturas perpetuándose en las formas del neocolonialismo, expresado en pobreza, ecogenocidio, exclusión, violencia, dominación y en todas las formas invisibles y ocultas de la colonialidad.

Cabe anotar, en palabras de Maldonado-Torres (2007) que:

(...) la colonialidad se refiere a un patrón de poder que emergió como resultado del colonialismo moderno, pero que en vez de estar limitado a una relación formal de poder entre dos pueblos o naciones, más bien se refiere a la forma como el trabajo, el conocimiento, la autoridad y las relaciones intersubjetivas se articulan entre sí, a través del mercado capitalista mundial y de la idea de raza. Así, pues, aunque el colonialismo precede a la colonialidad, la colonialidad sobrevive al colonialismo. La misma se mantiene viva en manuales de aprendizaje, en el criterio para el buen trabajo académico, en la cultura, el sentido común, en la auto-imagen de los pueblos, en las aspiraciones de los sujetos, y en tantos otros aspectos de nuestra experiencia moderna. (p.131).

$Y_{¿}$ Por qué no? en las formas y estrategias de la intervención social como demagogia y como asistencialismo religioso.

Es así como podremos entender las dinámicas diversas del quehacer y del desarrollo humano en el pluriverso social y cultural de América, sus realizaciones y obstáculos para las mismas, en esa especie de carimba que sobrevive en el espíritu de muchos pueblos sometidos, aplastados, por la cultura hegemónica.

En las comunidades, como plantea Grosso (2007), lo epistémico está enraizado en las prácticas, en la cotidianidad, en los sueños y búsquedas, en una corpo- 
ralidad que nos empeñamos en seguir viendo con los ojos de la Colonia, como si no se hubiesen construido rupturas, torsiones magistrales, espacio-tiempos otros, como construcciones translocales. Expresión que guarda el sentido de la transculturación en los términos propuestos por Ortiz (1986); los sujetos que representan una cultura territorial diaspórica, que cambian, seleccionan, hacen suya, apropian, resignifican el sentido del territorio y de la cultura, instalándose, reconstruyéndose permanentemente en su viajar, alimentando la resistencia contra hegemónica (Grimson, 2001).

La colonialidad impuesta en nombre del ideario cristiano dio pie a pensamientos disidentes, a otros pensamientos, a historias otras. Formas de pensamiento mediatizadas por las razones de violencia simbólica que se empeñan en hacer aparecer como la unificación impersonal y metafórica que impone y disfraza, oculta, se naturaliza y de violentación simbólica (Grosso, 2007), que no solo las han alimentado a lo largo de los siglos, sino que se siguen expresando. Entonces se expresa el doble vínculo, sobrepasando lo verbal como un enredo, una trama contextual, operacional, en las premisas o reglas del hábito. Se siente y se expresa haciendo. Tiene que ver con lo táctil, lo corporal, lo emotivo, lo afectivo; genera una torsión, una provocación.

Quijano (1997) dice que es hora de dejar lo que no somos, de asumir las implicaciones de lo que hemos sido; la hora de materializar en la praxis, el pensamiento y el sentimiento que nos permita trasegar el camino de la construcción al reconocimiento y al autorreconocimiento.

A esto apunta el Trabajo Social en su estrategia de intervención social, como lo plantean Orozco y López (2015),

El papel influyente de los actores sociales para exaltar el nivel de participación y aportación de la población en la realización de tareas comunitarias de contenido cultural y social, que eleven su protagonismo y promuevan su autogestión social en la solución de problemas y cambio 
de su entorno, es un tema de actualidad para el enfrentamiento de complejos problemas sociales, al cual diferentes disciplinas sociales, entre ellas Trabajo Social, han dedicado y dedican un gran esfuerzo investigativo y de intervención. (p.54)

Si bien comparto el anterior planteamiento en su intencionalidad implícita, observo que sigue instalado en la dicotomía sujeto-objeto, al conceder a los actores sociales, como investigadores o interventores sociales, el papel de influir y exaltar la participación de la población como ese otro ajeno, por fuera de las decisiones, ocultando la capacidad de gestión y de superación de las mismas; dicotomía que el enfoque decolonial pretende romper.

Los conocimientos ancestrales se expresan en las prácticas sociales y culturales como hilo conductor de los procesos de construcción de territorio y comunidad. La clave para la comprensión de los procesos históricos y actuales de las comunidades consiste en desentrañar las especificidades de las formas de comprender y ser de las mismas; los conocimientos propios que alimentados con unas fundamentaciones ancestrales les permitieron resistir el embate colonizador, y recrearse permanentemente como cultura y como sociedad.

Las prácticas cotidianas como discurso, en su sentido amplio, crean significados a partir de situaciones, que no son solo relativos, sino que están inscritos en la puesta en escena de la interlocución impregnada de identidades históricas y sociopolíticas. Interpretar las prácticas cotidianas como expresión de resistencia y la interlocución en que se hacen manifiestos, implica prestar atención a la mutua asimilación de las historias -identidades de los actores del discurso- como una práctica-política (Foucault, 1984), indagando por las construcciones translocales de resistencia (Laó-Montes, 2007), para enfrentar los dispositivos retóricos de estandarización -reducción- cultural naturalizados desde la Colonia, y que emergen como prácticas informales, extravagantes si se quiere, para dar sentido a la vida cotidiana dentro de su propio contexto; reaprendiendo permanentemente el entramado que da cuerpo al tejido relacional 
Se trata de textualizar la cotidianidad de la comunidad con el propósito de interlocutar con las formas de pervivencia de conocimiento propio en los procesos de construcción de territorio y tejido social; interrogar sobre cuáles son los conocimientos ancestrales que se expresan en sus prácticas cotidianas y, cómo se construye permanentemente el entramado de resistencia a través del cual se expresa ese conocimiento en las nuevas identidades e interculturalidades, en interrelación con los presupuestos históricos coloniales.

Por cuanto la vida humana no es solo política: las tramas del conflicto están en la cotidianidad; la lectura política es una construcción. Para encontrar los argumentos de las personas que participan en el conflicto, hay que determinar su origen territorial, su carga de imaginarios y mentalidades.

Dentro de ese límite no encontramos uniformidad. Reconocemos una heterogeneidad organizada, instituida imaginariamente en un momento determinado. La propuesta es interrogarse acerca de qué estamos hablando: de fronteras, de sentidos, de suturas, de circulación, de interculturalidad. La interculturalidad plantea que ninguna cultura es superior a otra, lo que no significa que no haya aspectos de una cultura que puedan ser valiosos para el intercambio cultural.

Urge indagar aquí ¿Cuál fue -acaso sigue siendo- el aparato existenciario producido por la colonialdad del ser? Si existen sujetos colonizados, ¿cómo se materializa la existencia de sujetos no colonizados? ¿Las tecnologías colonizan por igual el mundo de la vida? ¿Cómo construir praxis decolonial que pasa por el mundo de la vida?

Encontrando el pensamiento fronterizo que surge en ese silencio que grita y que puede dejar de existir porque es silencio y la historiografía oficial, cuando no lo borra, lo tergiversa, lo subsume en un mestizaje acorde con el borramiento de las características humanas y la historia escrita por esos seres disidentes. Por lo tanto hay que pensar desde el dolor, desde el grito, desde el silencio. 
La metanarrativa impuesta por la modernidad, descalificó como no competente el saber particular, local, regional, de la gente; el "saber histórico de las luchas", al considerarlo inferior, ingenuo.

Es necesario reescribir la historia para mostrar cómo en el pasado y en el presente, las comunidades han estado implicadas en las dinámicas socio culturales, económicas y políticas del país, la región y la ciudad. Por lo tanto urge visibilizarlos porque no han sido pasivos, han sabido jugar, adaptarse y muchas veces beneficiarse de diversas situaciones y contextos, pero sigue siendo evidente la poca mención que la historiografía oficial hace de estas presencias. Hay una franja "gris" en el proceso de inserción y construcción de territorio y comunidad, que riñe con la imagen idealizada y esencializada de las comunidades en el territorio americano. Es construir nuevas formas de aprender la presencia de los pueblos, como formas no occidentales de ser y estar en el mundo (Albán, 2006).

Lo histórico es cultural y es una marca de valor, es inherente, se construye en la cotidianidad, en interrelaciones y prácticas sociales y con la naturaleza. El valor no es trascendente, lo hacemos trascender en el discurso. La narrativa crea al otro. La cultura es fundamentalmente un sistema normalizador y, por tanto, las normas se aprenden en el proceso de socialización, y esto significa que las normas son compartidas, son prescriptivas, hechas por el hombre, visiblemente convencionales y políticamente determinadas por los grupos hegemónicos; son mandadas y prescritas por una forma política de poder y de organización social como el Estado.

Pero son al mismo tiempo variables, no homogéneas, dentro del grupo; cambiantes todo el tiempo. Es simultáneamente una continuidad cambiante, según procesos históricos, contextos y circunstancias. Así mismo tenemos que los sistemas culturales proponen sistemas de función simbólica. Se van fundiendo y crean nuevos horizontes. 
Cultura es una palabra que en su uso cotidiano conserva, simultáneamente, todos los significados que ha tenido a lo largo de la historia en su fundamentación occidental, cuyos orígenes se remontan a la Roma antigua; se usa con diversidad de sentidos, a veces irreconciliables y contradictorios, hasta llegar a la época del Descubrimiento, y sirve además, para diferenciar a ese "otro" hombre salvaje que se distinguía del "hombre del Renacimiento", que comportaba las condiciones y características sociales del canon europeo, y, que frente al "otro" se constituye en referente y modelo de cultura. Palabra que comienza a ser equivalente de civilización, de vida social urbana, con la pretensión homologante de ser universal, es decir, única, hegemónica, excluyente, fundamentada en verdades naturales, efectivamente naturalizadas a fuerza de cruz y espada, con la autoridad para imponerse, colonizar, civilizar y promover el desarrollo.

A pesar de esto, la sociedad humana ha dado muestras de su capacidad de romper los esquemas y resistir al avasallamiento. Por fuera del canon establecido, irrumpe la expresión y el reconocimiento de lo irracional, de lo subjetivo, en la comprensión de la vida, gestando en Occidente la clásica dualidad entre el mundo objetivo abordado por la ciencia positiva, y el mundo subjetivo por parte de la hermenéutica y la fenomenología. Esta dualidad sigue constituyendo la gran polaridad en las ciencias y metodologías del conocimiento social:

Es a partir de esta tensión que las ciencias sociales comienzan a interrogar sus certezas, en particular después de la segunda mitad del siglo XX. Se sitúan desde entonces en una nueva zona de contacto: ya no desde el podio de los observadores sino desde la posición de quien es partícipe de una realidad múltiple y conflictiva, definida por relaciones de poder, donde se debaten intereses muchas veces contradictorios y donde las líneas de la vida son siempre fragmentadas. Han reconocido que las interpretaciones son siempre subjetivas y los valores son relativos. Han partido sobre todo de aceptar que la dimensión imaginaria de la existencia es tanto o más real que la dimensión material y cuantitativa, por 
lo que resulta imposible universalizar los valores, las necesidades, así como las concepciones de lo legítimo, lo natural y lo verdadero, considerando la realidad como un producto social, histórico. (Serje, 2002, pp.127-128)

\section{Conclusiones}

La intervención social es un proceso de comunicación que se constituye en un sistema de propuestas con consecuencias para la vida concreta. Implica analizar críticamente las alternativas y seleccionarlas mediante la observación y la autoobservación para que conlleven a la superación de las formas críticas y permitan tomar decisiones acordes al requerimiento histórico y social (Bateson, 1998).

Para la intervención social es indispensable la consulta de la realidad concreta; se requiere del desarrollo de la investigación, se alimenta de ella y la impulsa a enriquecerse, más aún en el marco del modelo socio-crítico institucional.

Radica en lograr la ruptura de la dicotomía Sujeto-Objeto; no tomar como Objeto al ser humano que narra su vida, gracias a la escucha etnográfica que rompe la monoglosia jerárquica y vertical; así como no cuestionar la palabra del entrevistado referenciándola con la palabra de los académicos e ilustrados.

Es el reconocimiento de que múltiples voces escriben una misma historia; que las presencias diversas son incuestionables e irrepetibles históricamente. Es la construcción de una interculturalidad crítica, fundamentada en el respeto del diálogo de saberes y en la producción de conocimiento compartido, como investigación colaborativa.

Propone comprender, en los términos expuestos por Husserl (1986), las múltiples realidades participando y co-participando, produciendo lo que se conoce como "diálogo intercultural", "diálogo de saberes" o "investigación colaborativa interétnica" [...]. Acercándose a las prácticas rutinarias de los seres sociales, su comportamiento y reacciones emocionales. 
Es adoptar como una opción epistemológica, la perspectiva de ahondar en la comprensión y asimilación de los discursos y prácticas del movimiento social colombiano a lo largo de la historia. Resaltando el carácter diacrónico en sus expresiones históricas y contemporáneas contra todas las formas de colonialidad; y lograr la reivindicación del conocimiento y la praxis silenciada por los cánones históricos monumentalistas, $y$, por la narrativa académica tradicional, para avanzar en la posibilidad de construir y reconstruir el tejido social roto por décadas de ininterrumpida violencia.

\section{Referencias Bibliográficas}

Albán, A. (2006). Teniendo textos y saberes. Cinco hilos para pensar los estudios culturales, la colonialidad y la interculturalidad. Popayán, Colombia: Editorial Universidad del Cauca.

Bagly, B. y Botero, F. (1978). Organizaciones campesinas contemporáneas en Colombia. Un estudio de la ANUC. ERL, (1), 60-66.

Bateson, G. (1998). Pasos hacia una ecología de la mente. Una aproximación revolucionaria a la autocomprensión del hombre. Buenos Aires: Lumen, Argentina.

Eljach, M. (2006). La construcción Jurídica del Negro en la Colonia. Colombia: Ediciones Axis Mundi.

Foucault, M. (1984). Las Ciencias Humanas. Las palabras y las cosas. Barcelona: Planteta, Agostini.

García Marquez, G. (1983). La soledad de América Latina. Corporación Editorial Universitaria. Bucaramanga.

Grimson, A. (2001). Los límites de la cultura, Buenos Aires: Siglo XXI.

Grosso, J. (2007). "El revés de la trama. Cuerpos, semiopraxis e interculturalidad en contextos poscoloniales." Revista Arqueología Suramericana, 3 (2), 184-212.

Guzmán, C., Germán, F. y Umaña, L. (1977). La violencia en Colombia. Estudio de un proceso social. Punta de lanza, (8), Bogotá: Punta Lanza.

Husserl, E. (1986). The Crisis of European Sciences and the trascendental phenomenology. Evanston, Chicago: Northewestern University Press. 
Kalmanovitz, S. (1978). Desarrollo de la agricultura en Colombia. Edit. La Carreta, Bogotá.

Laó-Montes, A. (2007). Hilos descoloniales. Trans-localizando los espacios de la diáspora africana. Tabula Rasa, (7), 47-79.

Maldonado, N. (2007) "Sobre la colonialidad del ser: contribuciones al desarrollo de un concepto". En: Castro-Gómez Santiago y Ramón Grosfoguel Editores: El giro decolonial. Reflexiones para una diversidad epistémica más allá del capitalismo global. Bogotá: Siglo del Hombre Editores. pp.127-167.

Oquits, P. (1978). Violencia, conflicto y política en Colombia. Talleres Gráficos del Banco Popular, Bogotá.

Orozco, A. y López, E. (2015). "Hacia un modelo de gestión social y Desarrollo Humano Transformador”. En: Matices y horizontes de la investigación en Trabajo Social. Barranquilla: Ediciones Universidad Simón Bolívar, pp.53-111.

Ortiz, F. (1986). Los negros curros. La Habana, Cuba: Editorial de Ciencias Sociales.

Parada, J. (agosto 30, 2016). "Rumbo al plebiscito". En El Heraldo, domingo 14 de agosto.

Quijano, A. (1997). "Colonialidad del poder, cultura y conocimiento en América Latina”. Anuario Mariateguiano, IX(9), 137-148.

Riveros, H. (agosto 27, 2016). "Por favor, no lean el acuerdo" La Silla Vacía.

Sánchez, G. (julio al 22 de agosto de 2016). “Una reflexión sobre el conflicto y su resolución en Colombia”. Arcadia Semana.

Serje, M., Suaza, M. y Pineda, R. (2002). Palabras para desarmar. Bogotá: Ministerio de Cultura, Instituto Colombiano de Antropología e Historia.

Tocancipá, J. (2010). El mundo de la vida, crisis y etnografía: aproximaciones antropológicas a la fenomenología de Husserl. Anuario Colombiano de Fenomenología, (IV),199-217.

Valencia, L. y Ávila. A. (2016). "Los retos del posconflicto. Justicia, seguridad y mercados ilegales". Colombia: Ediciones B Colombia. 